DOI: $10.18203 / 2320-1770$. ijrcog20150052

\title{
Relationship and effect of duration of first stage of labor on second stage
}

\section{Leena MN, Muralidhar V. Pai*, Vidyashree G. Poojari}

Department of Obstetrics \& Gynaecology, Kasturba Medical College Manipal, Manipal University, Karnataka, India

Received: 20 February 2015

Revised: 04 March 2015

Accepted: 19 April 2015

\section{*Correspondence:}

Dr. Muralidhar V. Pai,

E-mail: drmvpai@yahoo.com

Copyright: (C) the author(s), publisher and licensee Medip Academy. This is an open-access article distributed under the terms of the Creative Commons Attribution Non-Commercial License, which permits unrestricted non-commercial use, distribution, and reproduction in any medium, provided the original work is properly cited.

\begin{abstract}
Background: Objective: To evaluate the relationship and effect of first stage of labor on second stage.

Methods: It was a prospective, observational study. A total of 132 subjects with cephalic presentation at or from $4 \mathrm{~cm}$ dilatation with or without intact membrane were included in the study. Women with more than $4 \mathrm{~cm}$ dilation were excluded from the study. The duration and complications of second stage were correlated with the duration of first stage.

Results: Out of 132 subjects, duration of labor was less than 3 hours in 79 subjects of which $52(65.8 \%)$ had shorter (less than 30 minutes) second stage. The duration of first stage was between 6 and 9 hours in 10 subjects of which 9 (90\% had longer (more than 30 minutes) second stage and 4 subjects had first stage lasting more than 9 hours of which $3(75 \%)$ had second stage lasting more than 1 hour. These findings were statistically significant $(P=0.001)$. As the duration of first stage increased the incidence of instrumental delivery was also increased however this was statistically not significant.

Conclusions: As the duration of first stage increases the duration of second stage and the incidence of instrumental/caesarean delivery increases.
\end{abstract}

Keywords: Labor, First stage, Second stage

\section{INTRODUCTION}

Labor is a physiological process involving sequential changes to enable delivery of the fetus. The durations of first and second stage of labor are variable and fraught with uncertainties. Friedman's research in 1950's gave exact definition for length and durations of various stages of labor. The "Friedman curve" established the norms for progression of normal labor. ${ }^{1}$ Based on his data normal cervical dilation during the active phase was $1.2 \mathrm{~cm} /$ hour for nulliparous women and $1.5 \mathrm{~cm} /$ hour for multiparous women. $^{2}$ Normal second stage for nulliparous and multiparas was estimated to be upto two hours and one hour, respectively. The duration of first stage of labor has an impact on the duration and conduct of second stage of labor. Longer the duration of first stage, longer will be the duration of second and hence the complications as the factors that influence the duration of first stage will have adverse impact on second stage. ${ }^{3}$ The objective of this study was to evaluate the relationship and effect of duration of first stage of labor on second stage.

\section{METHODS}

It was a prospective observational study conducted at department of Obstetrics and Gynaecology, Kasturba Medical College, Manipal, Manipal University, India between November 2013 and April 2014. Ethical committee clearance was obtained and the informed consent was taken from the subjects. 
A total of 132 subjects with uncomplicated singleton pregnancy with cephalic presentation and in active labor at $4 \mathrm{~cm}$ dilatation were recruited for the study. Women with cervical dilation $>4 \mathrm{~cm}$ were excluded from the study. Age, parity, gestational age, type of induction if any were noted. Standard labor room protocol of the hospital was used for the assessment and management of labor. Per vaginal examination was done every 4 hours in active labor. The variables studied included duration of first and second stages of labor, type of augmentation, use of epidural analgesia, mode of delivery and fetomaternal outcome. The data was analysed using SPSS software. Pearson's $\chi^{2}$ test was used to compare the variables and significance was assumed when $\mathrm{P}<0.5$.

\section{RESULTS}

A total of 132 subjects met the inclusion criteria and were recruited, of which 90 were under the age of 30 years and 42 were above 30 years. There were 87 primi and 45 multi gravida. Labor was augmented with artificial rupture of membranes and/or oxytocin in 89 subjects. Six subjects received epidural analgesia (Table 1).

Table 1: Demographic and labor characteristics $(\mathbf{n}=132)$.

\begin{tabular}{|lll|}
\hline Characteristics & $\begin{array}{l}\text { No. of } \\
\text { patients }\end{array}$ & $\begin{array}{l}\text { Percentage } \\
(\%)\end{array}$ \\
\hline Age $<30$ years & 90 & 68.1 \\
\hline Age $>30$ years & 42 & 31.9 \\
\hline Primi & 87 & 65.9 \\
\hline Multi & 45 & 34.1 \\
\hline $\begin{array}{l}\text { Augmentation with } \\
\text { ARM/Oxytocin }\end{array}$ & 89 & 67.4 \\
\hline No augmentation & 43 & 32.6 \\
\hline Epidural analgesia & 6 & 4.5 \\
\hline
\end{tabular}

The subjects were divided into subgroups based on duration of first stage (at intervals of 3 hours) and second stage (at intervals of 30 minutes) of labor as shown in Table 2. It was noted that 79 subjects had first stage under 3 hours of which $52(65.8 \%)$ had second stage lasting less than 30 minutes, $20(25.4 \%)$ between 31 and 60 minutes and $7(8.9 \%)$ more than 1 hour. The first stage was between 3 and 6 hours in 39 subjects of which 22 (56.4\%) had duration less than 30 minutes, 15 (38.5\%) had between 31 and 60 minutes and $2(5.1 \%)$ had more than 1 hour. The first stage lasted between 6 and 9 hours in 10 subjects of which only 1 had second stage less than 30 minutes whereas in $7(70 \%)$ the second stage of between 31 and 60 minutes and in $2(20 \%)$ it was more than 1 hour. Only 4 subjects had first stage more than 9 hours and out of them 3 (75\%) had second stage lasting more than 1 hour. These findings were also statistically significant $(\mathrm{P}<0.001)$.

Table 2: Relationship between the duration of first stage of labour with second stage $(n=132)$.

\begin{tabular}{|c|c|c|c|c|}
\hline \multirow{2}{*}{$\begin{array}{l}\text { Duration of } \\
\text { first stage } \\
\text { in hours }\end{array}$} & \multicolumn{3}{|c|}{$\begin{array}{l}\text { Duration of second stage of labour } \\
\text { in minutes }\end{array}$} & \multirow{2}{*}{$\begin{array}{l}\text { Total } \\
(132)\end{array}$} \\
\hline & $\begin{array}{l}\text { 0:00-0:30 } \\
N(\%)\end{array}$ & $\begin{array}{l}\text { 0:31-0:60 } \\
N(\%)\end{array}$ & $\begin{array}{l}>0: 60 \\
N(\%)\end{array}$ & \\
\hline $0-3$ & $52(65.8)$ & $20(25.4)$ & $7(8.9)$ & 79 \\
\hline $3-6$ & $22(56.4)$ & $15(38.5)$ & $2(5.1)$ & 39 \\
\hline $6-9$ & $1(10)$ & $7(70)$ & $2(20.0)$ & 10 \\
\hline \multirow[t]{2}{*}{$>9$} & 0 & $1(25)$ & $3(75.0)$ & 4 \\
\hline & 75 & 43 & 14 & 132 \\
\hline
\end{tabular}

Pearson Chi square test; $\mathrm{P}$ value $<0.001$

Table 3 shows the duration of first and second stage of labor in primi and multi gravida. Similar observations were made i.e. when the duration of first stage was lesser the duration of second stage was also shorter. In addition it was noted that majority $(43 / 45,955 \%)$ of multi had shorter first as well as second stage when compared to primi $(65 / 87,74.7 \%)$. These findings were also statistically significant $(\mathrm{P}=0.004)$.

Table 3: Relationship between duration of first stage of labor and second stage of labor in primi $\&$ multi (n=132).

\begin{tabular}{|c|c|c|c|c|c|c|}
\hline \multirow{2}{*}{$\begin{array}{l}\text { Duration of } \\
\text { first stage } \\
\text { in hours }\end{array}$} & \multicolumn{2}{|c|}{$\begin{array}{l}\text { Duration of second } \\
\text { stage of labour in } \\
\text { primi in minutes } \\
(\mathrm{n}=87)\end{array}$} & \multirow[t]{2}{*}{ Total } & \multicolumn{2}{|c|}{$\begin{array}{l}\text { Duration of second } \\
\text { stage of labour in } \\
\text { multi in minutes } \\
(n=45)\end{array}$} & \multirow[t]{2}{*}{ Total } \\
\hline & $\begin{array}{l}<0: 30 \\
\text { N (\%) }\end{array}$ & $\begin{array}{l}>0: 31 \\
N(\%)\end{array}$ & & $\begin{array}{l}<0: 30 \\
\mathrm{~N}(\%)\end{array}$ & $\begin{array}{l}>0: 31 \\
\text { N }(\%)\end{array}$ & \\
\hline $0-3$ & $26(54.1)$ & $22(45.9)$ & 48 & $26(83.8)$ & $5(16.2)$ & 31 \\
\hline $3-6$ & $16(61.5)$ & $11(38.5)$ & 27 & $6(50)$ & $6(50)$ & 12 \\
\hline $6-9$ & 0 & $8(100)$ & 8 & $1(50)$ & $1(50)$ & 2 \\
\hline \multirow[t]{2}{*}{$>9$} & 0 & $4(100)$ & 4 & 0 & 0 & 0 \\
\hline & 42 & 45 & 87 & 33 & 12 & 45 \\
\hline
\end{tabular}

Pearson Chi square test; $\mathrm{P}$ value $=0.004$ 
With respect to mode of delivery $16 / 132$ (12.1\%) had instrumental delivery and 5/132 (3.8\%) had second stage caesarean delivery. It was noted that when the duration of first stage was longer the subjects had more of instrumental or caesarean delivery. A total of 14 subjects had first stage more than 6 hours of which $5(35.7 \%)$ had either instrumental or caesarean delivery, Whereas out of 118 that had first stage less than 3 hours only 14 (11.8\%) had instrumental or caesarean delivery. However this finding was statistically not significant.

Out of 6 subjects that had epidural analgesia $3(50 \%)$ had prolonged first (more than 6 hours) and second stage (more than 30 minutes) and one had instrumental delivery. This finding was statistically not significant $(\mathrm{P}$ $=0.104$ )

Table 4: Mode of delivery $(n=132)$.

\begin{tabular}{|lllll|}
\hline $\begin{array}{l}\text { Duration } \\
\text { of first } \\
\text { stage in } \\
\text { hours }\end{array}$ & $\begin{array}{l}\text { Vaginal } \\
\text { delivery } \\
\text { without } \\
\text { instrument } \\
(\%)\end{array}$ & $\begin{array}{l}\text { Vaginal } \\
\text { delivery } \\
\text { with } \\
\text { instrument } \\
(\%)\end{array}$ & $\begin{array}{l}\text { Caesarean } \\
\text { section } \\
(\%)\end{array}$ & $\begin{array}{c}\text { Total } \\
n=132\end{array}$ \\
\hline $0-3$ & $72(91.1)$ & $5(6.4)$ & $2(2.5)$ & 79 \\
\hline $3-6$ & $30(76.9)$ & $7(18)$ & $2(5.1)$ & 39 \\
\hline $6-9$ & $7(70)$ & $3(30)$ & 0 & 10 \\
\hline$>9$ & $2(50)$ & $1(25)$ & $1(25)$ & 4 \\
\hline & $111(84.1)$ & $16(12.1)$ & $5(3.8)$ & 132 \\
\hline
\end{tabular}

Pearson Chi square test; $\mathrm{P}$ value $=0.104$

\section{DISCUSSION}

Multiple studies have cited labor progress different from that proposed by Friedman. Studies conducted by Zhang and co-workers showed that cervix dilated relatively slower in the active phase and dilated at a faster rate after $6 \mathrm{~cm}$ of dilation, compared with 2.5 hours under the Friedman curve. ${ }^{4}$ They proposed different labour curve for nulliparous women. ${ }^{5}$ Our study demonstrates that there is a definite relationship between first and second stage of labor with respect to duration and outcome as suggested by Friedman in 1950's. ' In our study the duration of second stage of labor was increased as the duration of first stage was increased in both primi and multi gravida. Similar findings were seen in the study conducted by Cohen WR and co-workers. ${ }^{6}$ A large observational study conducted at the University of Texas South-Western Medical Center from 2001 to 2012 showed that women with first stage greater than the $95^{\text {th }}$ percentile had a second-stage length greater than the $95^{\text {th }}$ percentile ${ }^{3}$.In addition it was noted that in multigravida both first and second stage were shorter. However the other factors like amniotomy or oxytocin augmentation, epidural analgesia did not seem to establish any statistically significant relationship. A prolonged second stage of labor predicts dystocia. ${ }^{7}$ Both maternal and neonatal morbidities increased with second stages more than 3 hours. $^{8}$ There is increased risk of postpartum haemorrhage, perineal lacerations and instrumental or caesarean delivery. ${ }^{9}$ Maternal and neonatal outcomes studied showed that prolonged length of the second stage of labor however was not associated with poor neonatal outcome but it was associated with increased maternal morbidity and operative delivery rates. ${ }^{10}$ In our study 5 $(35.7 \%)$ subjects had instrumental or caesarean delivery because of prolonged second stage which correlated well with prolonged first stage. A review article on safe prevention of primary caesarean delivery concluded that about $16 \%$ of pregnant women have second stage caesarean sections. ${ }^{11}$ In our study the incidence of second stage caesarean was $5 / 132(3.7 \%)$ and instrumental delivery was $16 / 132(12.1 \%)$.

Epidural analgesia is associated with a prolonged second stage and there is an increased rate of caesarean or instrumented vaginal delivery. ${ }^{12}$ However, it was not demonstrated as an independent risk factor for a prolonged labor. In our study $50 \%$ (3/6) of the subjects that had epidural analgesia had prolonged first and second stage of labor and only 1 had instrumental delivery.

\section{CONCLUSION}

As the duration of first stage increases the duration of second stage and the incidence of instrumental/caesarean delivery increases.

\section{Funding: No funding sources}

Conflict of interest: None declared

Ethical approval: The study was approved by the institutional ethics committee

\section{REFERENCES}

1. Friedman EA. Primigravid labor; a graphicostatistical analysis. Obstet Gynecol. 1955;6:567-89.

2. Cunningham FG, Leveno KJ, Bloom SL, Hauth JC, Rouse DJ, Spong CY. Normal labor and delivery. In: Cunningham FG, Leveno KJ, Bloom SL, Hauth JC, Rouse DJ, Spong CY, eds. Williams's Obstetrics. 23rd ed. New York (NY): McGraw-Hill; 2010.

3. Nelson DB, McIntire DD, Leveno KJ. Relationship of the length of the first stage of labor to the length of the second stage. Obstet Gynecol. 2013 Jul;122(1):27-32.

4. Zhang J, Troendle JF, Yancey MK. Reassessing the labor curve in nulliparous women. Am J Obstet Gynecol. 2002; 187:824-8.

5. Zhang J, Landy HJ, Branch DW, Burkman R, Haberman S, Gregory KD, et al. Consortium on safe labor. Contemporary patterns of spontaneous labor with normal neonatal outcomes. Obstet Gynecol. 2010;116:1281-7.

6. Cohen WR. Influence of the duration of second stage labor on perinatal outcome and puerperal morbidity. Obstet Gynecol. 1977;49:266. 
7. American College of Obstetricians and Gynecologists. Dystocia and augmentation of labor. ACOG Practice Bulletin No. 49. Obstet Gynecol. 2003;49:479-85.

8. Bleich AT, Alexander JM, McIntire DD, Leveno KJ. An analysis of second-stage labour beyond 3 hours in nulliparous. Am J Perinatol. 2012 Oct;29(9):717-22.

9. Brain H. Castro, Katheryn M. Nevarez. First and second stages of labor: risk factors, diagnoses, management. Am J Biomed. 2014 Apr;2(4):374-87.

10. Cheng YW, Hopkins LM, Caughey AB. How long is too long: Does a prolonged second stage of labor in nulliparous women affect maternal and neonatal outcome? Am J Obstet Gynecol. 2004;191:933-8.
11. Caughey AB, Cahill AG, Guise JM, Rouse DJ. Safe prevention of the primary caesarean delivery. American College of Obstetricians and Gynecologists (the College) and the Society for Maternal and Fetal Medicine. Obstet Gynecol. 2014;123:693-711.

12. Leighton BL, Halpern SH. The effects of epidural analgesia on labor, maternal, and neonatal outcomes: a systematic review. Am J Obstet Gynecol. 2002 May;186(5 Suppl Nature):S69-77.

DOI: $10.18203 / 2320-1770$. ijrog20150052

Cite this article as: Leena MN, Pai MV, Poojari VG. Relationship and effect of duration of first stage of labor on second stage. Int J Reprod Contracept Obstet Gynecol 2015;4:566-9. 